\title{
Дослідження явищ теплопровідності при мікрохвильовому сушінні матеріалу
}

\author{
І. Л. Бошкова ${ }^{1 \bowtie}$, Н. В. Волгушева ${ }^{2}$, М. Д. Потапов ${ }^{3 凶}$ \\ $1,2,3$ Одеська національна академія харчових технологій, вул. Канатна, 112, Одеса, 65039, Україна \\ $\triangle$ e-mail: ${ }^{1}$ boshkova.irina@gmail.com, ${ }^{2}$ natvolgusheva@gmail.com, ${ }^{3}$ dornot@te.net.ua \\ ORCID: ${ }^{1}$ https://orcid.org/0000-0001-5989-9223; ${ }^{2}$ https://orcid.org/0000-0002-9984-6502
}

\begin{abstract}
Досліджуються математичні моделі нагрівання матеріалів при дії внутрішніх джерел теплоти. Представлено модель теплопровідності, у якій дія мікрохвильового поля враховується як позитивне внутрішнє джерело теплоти. Визначається, що доцільність одержання аналітичних рішень пов'язана із практичним інтересом до мікрохвильового сушіння. Інформачія про розподіл температури в матеріалі важлива для різних технологічних прочесів, наприклад, сушіння зерна. Розглядається напівобмежений масив, температура якого в початковий момент часу у всіх точках однакова. Прийнято однокомпонентну модель, відповідно до якої шар розглядається як квазігомогене середовище з ефективними характеристиками. Негативне джерело теплоти враховує частку енергії, обумовлену потоком вологи випаруваної при сушінні матеріалу. Приймається експонентний характер зміни інтенсивності позитивного та негативного джерела по товщині шару. Для рішення рівняння теплопровідності застосований метод інтегрального перетворення Лапласа. Рішення диферениіального рівняння теплопровідності з початковими й граничними умовами I роду дозволило одержати формулу для розрахунку температури напівобмеженого масиву, що застосовно для умов, коли температура навколишнього середовища менше температури матеріалу. Ця умова відображає реальний фізичний процес мікрохвильового нагрівання. Аналізуються результати розрахунків температури води та щүільного шару зерна пшениці залежно від тривалості дії мікрохвильового поля $і$ його питомої потужності. Показано, що для одержання достовірних результатів важливим показником є значення коефічієнта корисної дії мікрохвильової камери. Проведені розрахунки вологовмісту й температури шару зерна пшениці для періоду постійної швидкості сушіння. Отримана залежність може застосовуватися при аналізі впливу тривалості нагрівання, вхідної потужності й початкових температур на розподіл температури по товщині шару.
\end{abstract}

Ключові слова: Мікрохвильове поле; Внутрішні джерела теплоти; Математична модель; Нагрівання; Сушіння; Температура; Вологовміст; Нестаціонарний стан

doi: https://doi.org/10.15673/ret.v55i4.1629

(C) The Author(s) 2019. This article is an open access publication

This work is licensed under the Creative Commons Attribution 4.0 International License (CC BY) http://creativecommons.org/licenses/by/4.0/

\section{1. Вступ}

Метою роботи є складання математичної моделі та одержання формули для розрахунку температури напівобмеженого масиву при мікрохвильовому нагріванні точними аналітичними методами. Математична модель теплопровідності запи- сується в диференціальному виді й грунтується на законі збереження енергії. Залежно від складності поставленого завдання, для рішення математичних моделей у диференціальному виді застосовують точні аналітичні методи, наближені й чисельні [1]. Застосування точних аналітичних методів дозволяє одержати формули для проведення розра- 
хунків, у якіх не $є$ присутньою погрішність наближення. Аналіз існуючих теоретичних подань про процеси перетворення енергії мікрохвильового поля у внутрішню енергію тіла [2 - 5] свідчить про особливу складність моделювання тепловологопереносу при мікрохвильовому (MX) нагріванні. $\mathrm{y}$ той же час уживають досить успішні спроби створення математичних моделей [6-8], що дозволяють одержати рішення деяких окремих завдань теплопровідності при дії внутрішніх джерел теплоти, наприклад, при мікрохвильовому нагріванні. Рівняння для розподілу температури в одиночній твердій сфері 3 урахуванням залежності коефіцієнта теплопровідності від температури при дії внутрішніх джерел теплоти представлене в [8]. Особливий інтерес представляють моделі, що базуються на підходах О.В. Ликова [1], в основі яких лежить рівняння теплопровідності параболічного типу. Рішення [1] описують температурне поле при дії внутрішніх джерел теплоти в умовах, при яких тепловий потік направлений від навколишнього середовища до поверхні матеріалу, що при мікрохвильовому нагріванні не виконується. Виникає необхідність в одержанні рішень в умовах напрямку теплового потоку від поверхні матеріалу в навколишнє середовище. Так, формула для розрахунку температури при мікрохвильовому сушін-ні для граничних умов III роду наведена в [9]. Однак складність формули для розрахунку температури приводить до появи областей з результатами, що не відображають фізичну сутність явищ теплопереносу.

Доцільність одержання аналітичних рішень пов'язана із практичним інтересом до мікрохвильового сушіння. Інформація про розподіл температури в матеріалі важлива для різних технологічних процесів, на приклад, сушіння насінного зерна.

\section{2. Математична модель теплопровідності 3 урахуванням дії внутрішніх джерел теплоти}

Розглядається напівобмежений масив, температура якого у всіх точках однакова й дорівнює $\mathrm{t}_{0}$. $\mathrm{V}$ момент часу $\tau_{0}$ масив поміщається в мікрохвильове поле, починають діяти внутрішні джерела теплоти. Приймається, що температура поверхні $t_{w}$ залишається постійної: виконуються граничні умови I роду. Дія мікрохвильового поля приводить до росту температури в масиві. Прийнято однокомпонентну модель, відповідно до якої шар розглядається як квазігомогенне середовище 3 ефектив- ними характеристиками. Приймається, що фізичні характеристики матеріалу не залежать від температури. Температура змінюється по координаті $x \mathrm{i}$ в часі $\tau$.

Об'ємний характер нагрівання матеріалу в мікрохвильовому полі дозволяє розглядати матеріал як середовище, у якому діють внутрішні позитивні джерела теплоти. Приймається експонентний характер зниження інтенсивності позитивного джерела по товщині шару відповідно до закону Ламберта-Бера:

$$
q_{v 1}=q_{v 10} \cdot e^{-\alpha x},
$$

де $q_{v 10}$ - максимальна питома потужність позитивного джерела теплоти, Вт/м ${ }^{3} ; \alpha$ - коефіцієнт поглинання електромагнітної енергії в шарі матеріалу, 1/м, $x$ - поздовжня координата, м.

Вихід вологи при сушінні представлявся дією негативного джерела теплоти:

$$
q_{v 20}=\rho \cdot N \cdot r,
$$

де $q_{v 20}$ - максимальна питома потужність негативного джерела теплоти, Вт/м ${ }^{3} ; r$ - питома теплота паротворення, Дж/кг, $\rho$ - щільність матеріалу, кг $/ \mathrm{M}^{3} ; N$ - швидкість сушіння, $1 / \mathrm{c}$.

Приймається експонентний закон зміни інтенсивності негативного джерела по товщині шару:

$$
q_{v 2}=q_{v 20} \cdot e^{-\beta x},
$$

де $\beta$-коефіцієнт загасання негативного внутрішнього джерела, $1 /$ м.

Математична модель представлена наступними рівняннями.

$$
\begin{aligned}
& \frac{\partial t(x, \tau)}{\partial \tau}=a \frac{\partial^{2} t(x, \tau)}{\partial x^{2}}+\frac{q_{v 10}}{c \cdot \rho} e^{-\alpha x}+\frac{q_{v 20}}{c \cdot \rho} e^{-\beta x} \\
& t(x, 0)=t_{0} ; \frac{\partial t(\infty, \tau)}{\partial x}=0, t(0, \tau)=t_{w}=\text { const }
\end{aligned}
$$

де $a$ - коефіцієнт температуропровідності, $\mathrm{m}^{2} / \mathrm{c} ; c-$ теплоємність матеріалу, Дж/(кг.К).

Для рішення рівняння (4) був застосований метод інтегрального перетворення Лапласа.

\section{3. Аналіз зміни температури масиву при мікрохвильовому сушінні}

\section{1. Результат рішення математичної мо-} делі теплопровідності

Рішення диференціального рівняння теплопровідності (4) з початковими й граничними умовами (5) дозволило одержати формулу для розрахунку температури напівобмеженого масиву, 
що застосовно для умов, коли температура навколишнього середовища менше температури матеріалу. Ця умова відображає реальний фізичний процес мікрохвильового нагрівання.

$$
\begin{aligned}
& t(x, \tau)=\left(1-\operatorname{erfc} \frac{x}{2 \sqrt{a \tau}}\right) t_{0}+\operatorname{erfc} \frac{x}{2 \sqrt{a \tau}} \cdot t_{w}- \\
& -\frac{q_{v 10}}{c \rho a \alpha^{2}}\left[\begin{array}{l}
e^{-\alpha x}-\frac{1}{2} e^{\gamma^{2} a \tau-\alpha x} \operatorname{erfc}\left(\frac{x}{2 \sqrt{a \tau}}-\alpha \sqrt{a \tau}\right) \\
+\frac{1}{2} e^{\gamma^{2} a \tau+\alpha x} \operatorname{erfc}\left(\frac{x}{2 \sqrt{a \tau}}+\alpha \sqrt{a \tau}\right)-\operatorname{erfc} \frac{x}{2 \sqrt{a \tau}}
\end{array}\right]- \\
& \left.-\frac{q_{v 20}}{c \rho a \beta^{2}}\left[\begin{array}{l}
e^{-\beta x}-\frac{1}{2} e^{\beta^{2} a \tau-\beta x} \operatorname{erfc}\left(\frac{x}{2 \sqrt{a \tau}}-\beta \sqrt{a \tau}\right) \\
+\frac{1}{2} e^{\beta^{2} a \tau+\beta x} \operatorname{erfc}\left(\frac{x}{2 \sqrt{a \tau}}+\beta \sqrt{a \tau}\right)-\operatorname{erfc} \frac{x}{2 \sqrt{a \tau}}
\end{array}\right], 6\right)
\end{aligned}
$$

де $a$ - коефіцієнт температуропровідності, м²/c; $\alpha$ коефіцієнт поглинання електромагнітної енергії, $\mathbf{M}^{-1}, \beta$ - коефіцієнт загасання негативного внутрішнього джерела, ${ }^{-1}$, нижній індекс 0 при питомій потужності показує, що величина відноситься до максимального значення.

3.2. Апробація розрахункової формули для температури напівобмеженого масиву без ураху-вання виходу вологи

Перевірка працездатності розрахункової формули проведена на зерні пшениці й воді. На рисунку 1 наведені результати розрахунків температур зерна й води залежно від тривалості впливу $\mathrm{MX}$ поля при $q_{v 20}=0$. Вихідні дані для розрахунку наступні: початкові температури матеріалу та середовища рівні: $t_{w}=t_{0}=20{ }^{\circ} \mathrm{C}$, коефіцієнт поглинання для води $\alpha_{w}=125 \mathrm{~m}^{-1}$, коефіціснт поглинання для зерна $\alpha_{w}=30 \mathrm{~m}^{-1}$. Розрахунок температури води й зерна при однаковій ефективності перетворення мікрохвильової енергії у внутрішню енергію тіла, при цьому коефіцієнт корисної дії (ККД) камери $\eta=1$, показав, що температурні криві для води (лінії 3,4 ) розташовуються нижче кривих для зерна (лінії 1,2). Це пояснюється тим, що для коректного зіставлення температур необхідно враховувати значення діелектричних характеристик матеріалу (так, для води при $20^{\circ} \mathrm{C} \varepsilon^{\prime \prime}=82$, для зерна $\varepsilon^{\prime \prime}=2,6$ ). Iз цією метою необхідно використовувати дані по ККД мікрохвильової камери ๆ. Ефективність поглинання мікрохвильової енергії водою вище, ніж зерном. ККД камери при нагріванні води був близький до 1 .

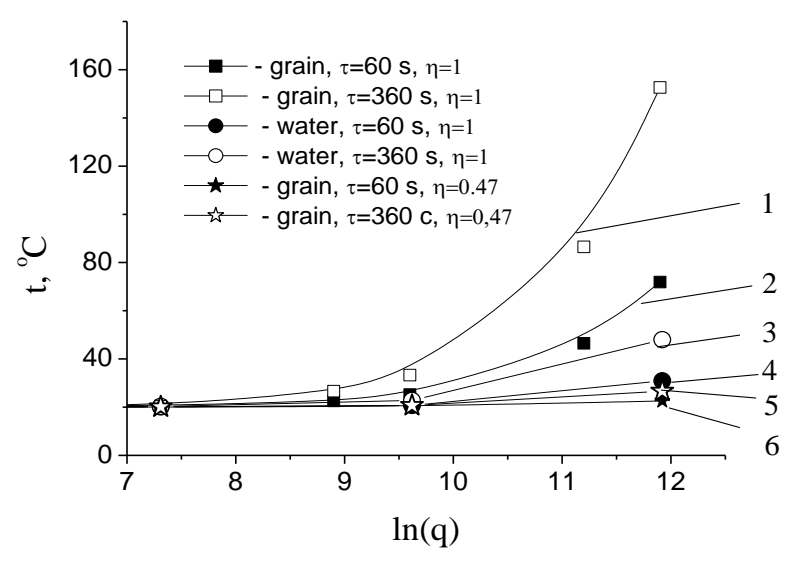

Рисунок 1 - Зміна температури тіла при мікрохвильовому нагріванні для $x=10$ мм: 1 - зерно, $\eta=1$, $\tau=360 \mathrm{c} ; 2$ - зерно, $\eta=1, \tau=60 \mathrm{c} ; 3-$ вода, $\eta=1$, $\tau=60 \mathrm{c} ; 4-$ вода, $\eta=1, \tau=360 \mathrm{c} ; 5$ - зерно, $\eta=0,47$, $\tau=60 c ; 6$ - зерно, $\eta=0,47, \tau=360 c$.

Експериментальна залежність для визначення ККД камери при іiі завантаженні зерном наведена в [10]. Відповідно до цієї залежності для зерна пшениці масою 100 гр ККД $\eta=0,47$. У цьому випадку розрахунок привів до розподілу температурних кривих, що правильно представляє фізичний процес мікрохвильового нагрівання. Температура зерна (лінії 5,6$)$ розташовуються нижче, ніж температура води, і їхні значення задовільно корелюються з експериментальними [10].

\section{3. Апробація розрахункової формули напівоб- меженого масиву з урахуванням виходу вологи}

У періоді постійної швидкості сушіння приймається, що вологовміст кожного шару в часі змінюється за лінійним законом (7). Зміна вологовмісту по шарах углиб матеріалу визначається по залежності (8).

$$
\begin{aligned}
& u=u_{0}-N_{i} \cdot \tau \\
& N_{i}=N_{0} e^{-\beta x}
\end{aligned}
$$

де $N_{i}$ - швидкість сушіння і-го шару, $1 / \mathrm{c} ; N_{0}$ - швидкість сушіння верхнього шару, $1 / \mathrm{c}$.

По наведеним вище залежностях (6), (7) на основі пакета прикладних програм MAPLE 15 отриманий розподіл вологовмісту й температури матеріалу в процесі сушіння при мікрохвильовому підведенні теплоти. Прийняті в розрахунку значення максимальних питомих потужностей джерел $q_{v 10}$ i $q_{v 20}$, а також коефіцієнтів ослаблення $\alpha$ i $\beta$, наведені в табл.1. 
Таблиця 1 - Вихідні дані для розрахунку полів вологовмісту й температури.

\begin{tabular}{|l|l|l|l|l|}
\hline \multicolumn{1}{|c|}{$P, \mathrm{BT}$} & $\begin{array}{c}q_{v 10}, \\
\mathrm{BT} / \mathrm{M}^{3} .\end{array}$ & $\begin{array}{c}q_{v 20} \cdot 10^{5}, \\
1 / \mathrm{c} .\end{array}$ & $\alpha, 1 / \mathrm{M}$. & $\beta, 1 / \mathrm{M}$. \\
\hline 160 & 110 & $-4,26$ & 30,2 & $-6,6$ \\
\hline 240 & 165 & $-8,9$ & 30,2 & $-6,6$ \\
\hline 400 & 275 & $-13,9$ & 30,2 & $-6,6$ \\
\hline
\end{tabular}

На рисунку 2 наведені криві зміни вологовмісту й температури. Профіль температури по товщині шару, при переході від періоду прогріву до періоду постійної швидкості сушіння, змінюється (рис.2 б). Якщо в період прогріву температура убуває по експоненті, то в періоді постійної швидкості сушіння ця залежність змінюється стає близької до лінійного закону (крива 3 рис. 2б) i переходить до опуклого виду кривої.
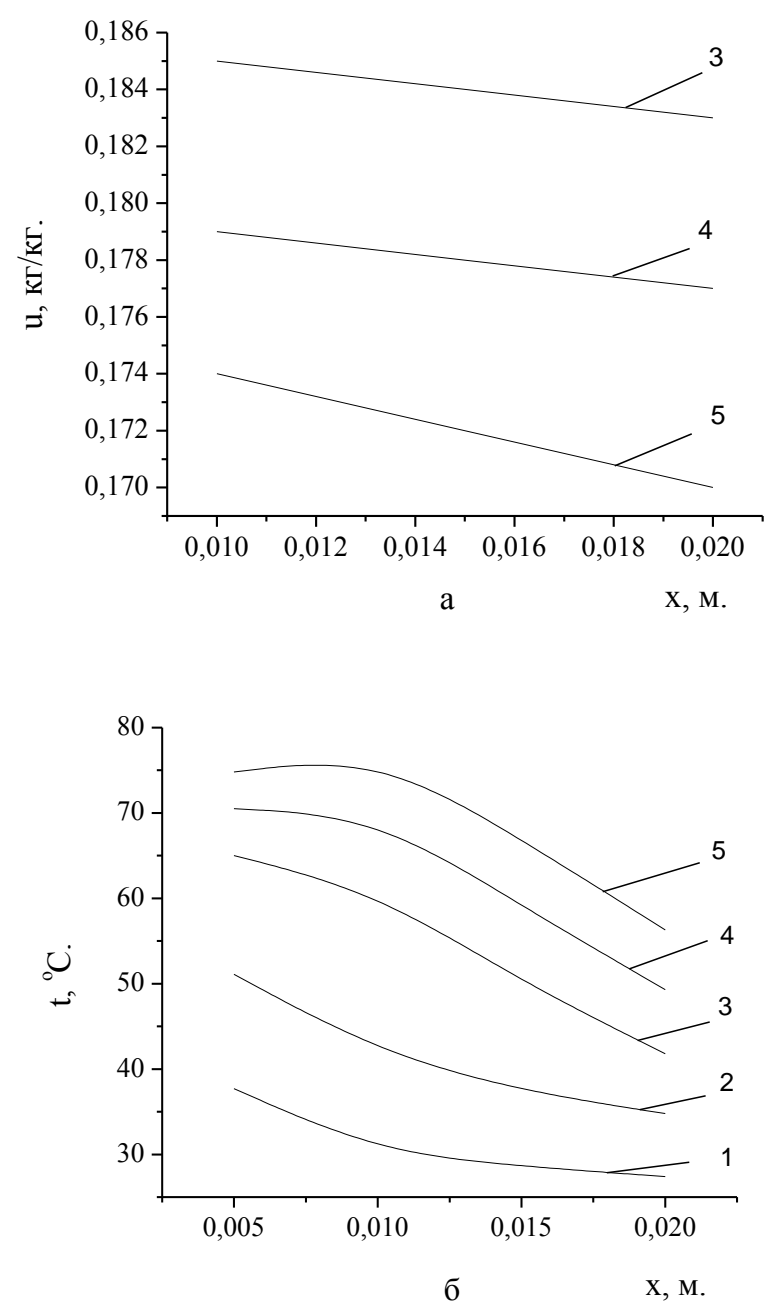

Рисунок 2 - Зміна вологовмісту (а) та температури (б) по товщині шару в процесі сушіння при потужності МХ джерела $N_{\text {вих }}=160 \mathrm{Bm}$.

Період прогріву: 1-1- $\tau=60 \mathrm{c} ; 2-2-\tau=120 \mathrm{c}$;

Період постійної швидкості сушіння:

3-3- $\tau=360 c ; 4-4-\tau=480 c ; 5-5-\tau=600 c$.
Для визначення середньої швидкості сушіння зерна може бути запропонована емпірична залежність (9), справедлива при $200 \leq q \leq 1285 \mathrm{BT} / к \Gamma$ із погрішністю $\pm 15 \%$ [10].

$$
N=1,58 \cdot 10^{-7}(q)^{1,17}, \mathrm{c}^{-1}
$$

де $q=Q / M$ - питомий тепловий потік, Вт/кг.

Для розрахунку корисного теплового потоку $Q$ пропонується формула (10), що враховує споживану від мережі електроенергію $P$, ККД мікрохвильової камери $\eta$ і ККД магнетрона $\eta_{m}$ :

$$
Q=P \cdot \eta \cdot \eta_{m}, \text { В Т }
$$

Установлено, що аналітичні залежності для розрахунку температур матеріалу при сушінні, отримані з рішення рівняння теплопровідності 3 урахуванням двох джерел теплоти, задовільно працюють в області режимних параметрів, що відповідають режимам сушіння зернових: швидкість сушіння $N=10^{-5} \ldots 10^{-4} \mathrm{c}^{-1}$, початковий вологовміст $u=0,2$ кг/кг [10]. Розрахунок температур по розроблених математичних моделях 3 урахуванням двох внутрішніх джерел теплоти дозволяє одержувати задовільні дані й прогнозувати тепловий стан матеріалу в довільний момент часу.

\section{4. Висновки}

Математична модель теплопровідності напівобмеженого масиву, що враховує дію двох джерел тепла, позитивного й негативного, задовільно описує процес нагрівання шару матеріалу в мікрохвильовому полі 3 урахуванням випару волога при сушінні. Отримана аналітична залежність для розрахунку локальних температур напівобмеженого масиву в умовах мікрохвильового нагрівання може застосовуватися при аналізі впливу тривалості нагрівання, вхідної потужності й початкових температур на розподіл температур по товщині шару.

\section{Література}

1. Лыков А. В. Теория теплопроводности. - М., Высшая школа, 1967. - 600 с.

2. Feng H., Yin Y., Tang J. Microwave Drying of Food and Agricultural Materials: Basics and Heat and Mass Transfer Modeling. // Food Engineering Reviews. - June 2012. - Vol. 4. - Is. 2. - P. 89-106.

3. Mathematical modeling of microwave-vacuum drying of vegetative mas / S.Braginets et al. 17th International Scientific Conference Engineering for Rural Development: Jelgava. 23-25.05.2018. P. 585-591. 
4. Thostenson E. T., Chou T. W. Microwave processing: fundamentals and applications. Composites Part A: Applied Science and Manufacturing. 1999. Vol. 30, № 9. P. 1055-1071.

5. Newnham R. E., Jang S.J., Xu M. Fundamental interaction mechanisms between microwave and matter. Ceramic Transactions. 1991. Vol. 21. P. 23-48. 6. Modelling of microwave assisted hot-air drying and microstructural study of oilseeds / M. Hemis et al. 4 Int Journal Agriculture \& Biologically Engineering. 2016. Vol. 9, №6. P. 167-177.

7. Campanone L. A., Zaritzky N. E. Mathematical analysis of microwave heating process. Journal of Food Engineering. 2005. №69. P. 359-368.

8. Hussein K. Jobair. Analytical and Numerical Study of the Temperature Distribution for a Solid
Sphere subjected to a Uniform Heat Generation. International Journal of Computer Applications. 2017. Vol. 168, No.2. P. 30-37.

9. Kolesnychenko N., Volgusheva N., Boshkova I. Analytical study of the processes of thermal conductivity at high intensity heating // East-European Journal of Enterprise Technology: Energy-saving technologies and equipment. - 2016. - Vol 5. - No. 8 (83). P. 26-31.

10. Assessment of efficiency of drying grain materials using microwave heating / I. Boshkova et al. // EastEuropean Journal of Enterprise Technology: Energysaving technologies and equipment. - 2019. - Vol 1/8 (97). - P. 78-86.

Отримана в редакції 22.05.2019, прийнята до друку 02.07.2019

\title{
A study of the phenomena of thermal conductivity during microwave dry- ing of the material
}

\author{
I. Boshkova ${ }^{1 \bowtie}$, N. Volgusheva ${ }^{2 \bowtie}$, M. Potapov $^{3 凶}$ \\ ${ }^{1,2,3}$ Odessa National Academy of Food Technologies, 112 Kanatnaya Str., Odessa, 65039, Ukraine \\ $\triangle$ e-mail: ${ }^{1}$ boshkova.irina@gmail.com, ${ }^{2}$ natvolgusheva@gmail.com, ${ }^{3}$ dornot@ te.net.ua \\ ORCID: ${ }^{1}$ https://orcid.org/0000-0001-5989-9223; ${ }^{2}$ https://orcid.org/0000-0002-9984-6502
}

\begin{abstract}
Mathematical models of heating materials under the action of internal heat sources are studied. A thermal conductivity model is presented in which the action of the microwave field is taken into account as a positive internal heat source. It is determined that the feasibility of obtaining analytical solutions is associated with a practical interest in microwave drying. Information on the temperature distribution in the material is important for various technological processes, for example, the drying of grain. A semi-infinity body is considered, whose temperature at the initial time is the same at all points. One-component model is adopted, according to which the layer is considered as a quasi-homogeneous medium with effective characteristics. A negative heat source takes into account the fraction of energy caused by the flow of moisture evaporated during drying of the material. The exponential nature of the change in the intensity of the positive and negative source along the thickness of the layer is assumed. The Laplace integral method is used to solve the thermal conductivity equation. The solution of the differential equation of thermal conductivity with initial and boundary conditions of the first kind made it possible to obtain a formula for calculating the temperature of a semi-infinite body, which is applicable for conditions when the ambient temperature is less than the material temperature. This condition reflects the actual physical process of microwave heating. The results of calculations of the temperature of water and a dense layer of wheat grain are analyzed depending on the duration of the microwave field and its specific power. It is shown that in order to obtain reliable results, an important indicator is the efficiency of the microwave chamber. The moisture content and temperature of the wheat grain layer were calculated for a constant drying rate. The obtained dependence can be used in the analysis of the influence of heating duration, input power and initial temperatures on the temperature distribution along the thickness of the layer.
\end{abstract}

Key words: Microwave Field; Internal Sources of Heat; Mathematical Model; Heat; Drying; Temperature; Moisture Content; Unsteady State. 


\section{References}

1. Lykov, A. V. (1967) Teoriya teploprovodnosti. M., Vysshaya shkola, 600.

2. Feng, H., Yin, Y., Tang, J. (2012) Microwave Drying of Food and Agricultural Materials: Basics and Heat and Mass Transfer Modeling. Food Engineering Reviews, 4, 2, 89-106.

3. Braginets, S. et al. (2018) Mathematical modeling of microwave-vacuum drying of vegetative mas. 17th International Scientific Conference Engineering for Rural Development: Jelgava, 585-591.

4. Thostenson, E. T., Chou, T. W. (1999) Microwave processing: fundamentals and applications. Composites Part A: Applied Science and Manufacturing, 30, 9, 1055-1071.

5. Newnham, R. E., Jang, S. J., Xu, M. (1991) Fundamental interaction mechanisms between microwave and matter. Ceramic Transactions, 21, 23-48.

6. Hemis, M. et al. (2016) Modelling of microwave assisted hot-air drying and microstructural study of oilseeds. 4 Int. Journal Agriculture \& Biologically
Engineering, 9, 6, 167-177

7. Campanone, L. A., Zaritzky, N. E. (2005) Mathematical analysis of microwave heating process. Journal of Food Engineering, 69, 359-368.

8. Hussein, K. Jobair. (2017) Analytical and Numerical Study of the Temperature Distribution for a Solid Sphere subjected to a Uniform Heat Generation. International Journal of Computer Applications, 168, 2, 30-37.

9. Kolesnychenko, N., Volgusheva, N., Boshkova, I. (2016) Analytical study of the processes of thermal conductivity at high intensity heating. East-European Journal of Enterprise Technology: Energy-saving technologies and equipment, 5, 8 (83), 26-31.

10. Boshkova, I. et al. (2019) Assessment of efficiency of drying grain materials using microwave heating. East-European Journal of Enterprise Technology: Energy-saving technologies and equipment, 1/8 (97), $78-86$.

Received 22 May 2019

Approved 02 July 2019

Available in Internet 05 September 2019 